\title{
Work Stress, Nonwork Stress, and Health
}

\author{
Susan Klitzman, ${ }^{1}$ James S. House, ${ }^{2}$ Barbara A. Israel, ${ }^{3}$ \\ and Richard P. Mero ${ }^{2}$
}

Accepted for publication: October 9, 1989

\begin{abstract}
This paper examines the interface between work stress and nonwork stress and how it relates to health. Results indicate that the way people feel at work is largely a function of conditions at work. Similarly, the way people feel outside of work is largely a function of things that occur outside the job. Both work and nonwork stress are independently associated with physical and mental health, although the relationship between nonwork stress and health is slightly stronger. Excessive demands or stresses in one domain can interfere with life in the other. Such conflict operates equally in both directions. When present it can be an added source of stress and adversely affect health. Taken together these findings suggest that the stress people experience at work is not simply a reflection of their "personal problems." This has implications for the design of health promotion and stress prevention programs in the workplace.
\end{abstract}

KEY WORDS: health; work; nonwork; stress.

Preparation of this article has been supported by Grant 501AA06553 from the National Institute on Alcohol Abuse and Alcoholism and Grant 5T32 MH16806 from the National Institute of Mental Health. The authors wish toacknowledge Ann Kinney for her assistance in data analysis and the members of the Worksite Stress and Wellness Committee for emphasizing, at the onset, the importance of examining both job and nonjob sources of stress in this project. We also thank Sue Andersen for her assistance in preparing this manuscript.

${ }^{1}$ New York City Department of Health, New York, New York.

${ }^{2}$ Institute for Social Research and Department of Sociology, University of Michigan, Ann Arbor, Michigan 48109.

${ }^{3}$ School of Public Health, University of Michigan, Ann Arbor, Michigan 48109. 


\section{BACKGROUND}

There is now a substantial body of evidence that psychosocial aspects of the work environment may affect individual health and well-being. Several studies have shown that conditions in the work environment, which are perceived by the individual as stressful - such as job demands or pressures, poor social relationships, and dirty or noisy physical environments - are associated with physiological changes (Frankenhaeuser and Gardell, 1976; Levi, 1981), psychological distress and somatic complaints (Quinn and Shepard, 1977; Cooper and Payne, 1978; Caplan et al., 1980; House, 1980; Israel et al., 1989) and possibly more serious life-threatening illness such as cardiovascular disease (Kittel et al., 1980; Karasek et al., 1981; Haynes 1987).

Despite the consistency of findings across a diversity of studies, work stressors have been able to explain only a relatively small portion of the variance in health outcomes in any single study. This suggests that other factors may play a role in the stress-illness process. Two additional types of stressors outside of work which also play a role in the stress-illness process have been identified in numerous studies. These are chronic daily hassles, such as financial, marital, and family conflicts, and major life events, such as family illness, death, and other losses (Dohrenwend and Dohrenwend, 1981; Kanner et al., 1981; DeLongis et al., 1982; Thoits, 1983).

To date, there has been relatively little research on the combined impact of work and nonwork stresses on health, especially compared to the number of investigations which have focused on one or the other of these two domains. At first glance, the limited research in this area appears to yield conflicting findings. A number of recent studies have reported positive associations between the number of social roles a person occupies (e.g., parent, spouse, worker) and good health (e.g., Gove and Geerken, 1977; Waldron, 1980; Verbrugge, 1983; Gore and Mangione, 1983). At the same time, other researchers have shown that the impact of employment, marriage, and parenting status on health differs depending on the particular characteristics of those roles. People occupying multiple roles, whose jobs are challenging, experience fewer health problems than people in routinized jobs (Muller, 1986; Verbrugge, 1986). Conversely, it has been shown that excessive demands either at work or outside of work have been associated with adverse health risks (Burke and Bradshaw, 1981). The latter set of findings underscores the need to examine specific role characteristics rather than simply just the number of roles a person occupies (Froberg et al., 1986).

There is a sparsity of data on the combined impact of work and nonwork stress on health, and the relationship between the two is not clearly understood. In general, research and programs in this area have assumed 
two opposing starting points. The first makes an a priori assumption about the centrality of work and has focused on the impact of work on nonwork life. Research has been especially concerned with how work schedules (e.g., shiftwork, weekend work, number of hours worked) and family employment patterns (e.g., dual vs. single wage-earners) affect the quality of family life (e.g., time spent on childcare, housework, and leisure activities and work/family interference) (Kanter, 1977; Staines and Pleck, 1983). Three distinct hypotheses regarding the nature of this relationship have been suggested within this area of research: (1) spillover - experiences on the job carry over into the nonwork arena; (2) compensation-people make up for the deficiencies in their work environment in their choice of family and leisure activities; and (3) compartmentalization - what goes on at work is completely separate from what goes on outside of work. The spillover hypothesis has received the most consideration (see, for example, review by Staines, 1980). Evidence of the influence of work on nonwork activities has been found in at least two longitudinal studies (Karasek, 1981; Kohn and Schooler, 1978).

The second research trend focuses on the reverse relationship: the impact of nonwork on working life. There is some evidence that family pressures may negatively affect work opportunities and performance (Papanek, 1973). More recently, one study reported that "daily hassles" - both work and nonwork related - were significantly associated with absenteeism (although not with job performance) (Ivancevich, 1986).

Given that these two bodies of research have been largely separate from one another, it is difficult to draw conclusions about the relative importance of work and nonwork life. It has been argued that work is likely to influence nonwork more than the other way around because for most people work "lacks the flexibility and malleability of nonwork. . .e.g., things like leisure activities" (Breer, Locke, and Meisner, cited by Staines, 1980, p. 114; Staines and Pleck, 1983). In support of this position, one recent study found that work produces greater sources of work-nonwork conflict than nonwork (Beutell and O'Hare, 1987).

In addition to making a priori assumptions regarding the causal importance of one area versus the other, studies of work-nonwork conflict rarely examine the impact on health. The focus is generally on conflict between the two domains, the impact of work on family responsibilities, and leisure activities on job performance.

Recent growing concern with health in the workplace has provided new impetus for the study of the relation of work and nonwork to each other and to health. Many workplaces have now implemented health promotion, employee assistance, stress management, and stress reduction programs. The proliferation of these programs reflects, in part, many employers' concerns with reducing health care costs, which have been rising steadily in the post 
WWII era (Navarro, 1976; Roemer, 1984). Employers bear a significant portion of health care costs in the form of insurance premiums and lost workdays due to illness, injury, and lost productivity (Fielding, 1984). The major strategy for health promotion in the workplace is individually based, emphasizing the role of such life-style factors as diet, smoking, alcohol intake, and physical activity in the etiology of major chronic diseases facing our society today (House and Cottington, 1986). By focusing on individual habits and health behaviors, this approach assumes (either implicitly or explicitly) that nonwork factors play a more important role in disease causation than do conditions in the work environment.

In summary, previous research suggests that work and nonwork have some effect on each other, but there is inadequate evidence regarding their relative importance. At present, there does not appear to be consistent empirical support for the predominance of one set of factors over the other. Both work and nonwork sources of stress have been linked with adverse health outcomes in separate investigations. Very little is known about their combined impact on health.

\section{SCOPE}

The purpose of this article is to examine the relationship among sources of stress at work, sources of stress outside of work, and health. Data are drawn from the first wave of a longitudinal study, aimed at identifying sources of workplace stress and developing programs to reduce stress and strengthen psychosocial factors that may mediate the negative effects of stress on health and quality of worklife. The theoretical framework is based on a broad model of psychosocial stress and health. A detailed description of the rationale and methodology of the larger project have been provided elsewhere (Israel, Schurman, and House, 1989).

Figure 1 provides a framework for examining the relationships among sources of stress, feelings, and health. Each of the arrows in the model (Fig. 1) reflects a question or series of questions to be explored in the analyses. Specifically, this article focuses on the following questions:

1. What is the nature of the relationship between stress at work and stress outside of work, e.g., spillover, compartmentalization, or compensation (Arrow 1)?

2. Related to this, to what extent does stress in each domain of life produce conflict or interference between work and nonwork (Arrow 2)?

3. What is the relationship of work stress and nonwork stress, respectively, to health (Arrows 3a and 3b)? 


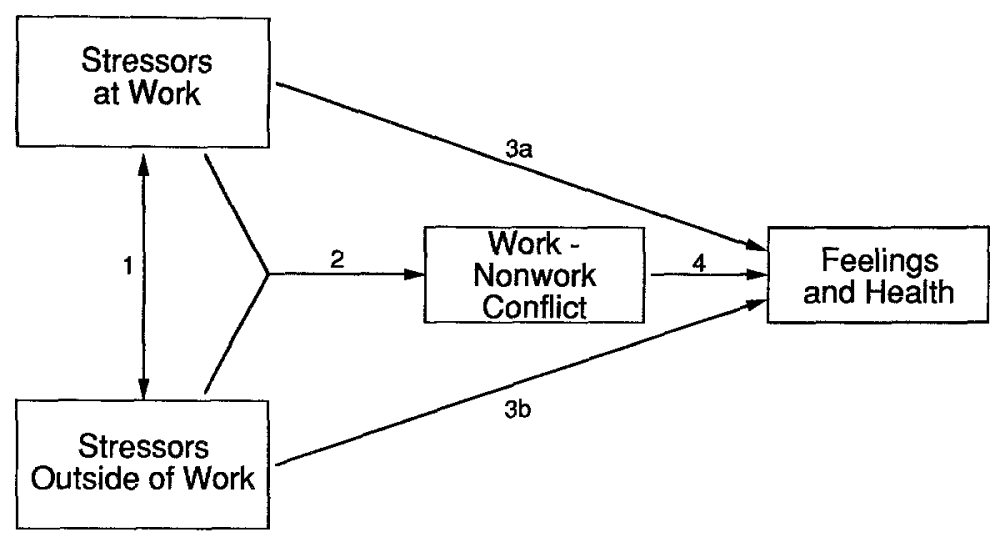

Fig. 1. Conceptual framework of the relationship among sources of stress, work-nonwork conflict, and feelings and health.

4. Is conflict or interference between work and nonwork situations related to health, over and above the combined additive effects of work and nonwork stress, respectively (Arrow 4)? And to what extent may work-nonwork conflict mediate the relationship of work or nonwork stress to health?

\section{SUBJECTS AND METHODS}

\section{Study Population}

The study population consists of all hourly and salaried employees in a component-parts plant of a major manufacturing corporation located in a medium-sized urban area in Michigan.

Data are drawn from a survey of employees which was carried out during April 1986. Joint union and management cooperation was obtained to conduct the study on site. Employees were informed that their participation was completely voluntary and their responses would be kept totally confidential. Data were collected using a 45-min to 1-hr self-administered questionnaire, which employees filled out during their regular working hours. Surveys were mailed to employees who were not present in the plant (e.g., those on vacation or medical leave). There was a total of 1036 eligible employees, and $680(66 \%)$ participated in the study. Results are reported here for 630 employees. Fifty surveys were excluded from these analyses because they contained large amounts of missing data. This was due primarily to 
scheduling problems during the data collection period, which prevented employees from completing the surveys.

The mean age for respondents was 43 at the time the data were collected. Ninety percent of the sample were male; $10 \%$ were female. Their ethnic background was a follows: $80 \%$ white; $17 \%$ black; and 3\% other (e.g., Asian, Hispanic, or Native American). The majority of respondents ( $73 \%$ ) was married. Eighty-four percent of the sample had at least a high-school education, with $13 \%$ having completed college. Respondents had worked an average of 10 years at the plant, and 20 years for the company. Eighty-two percent were hourly employees and $18 \%$ were salaried employees.

\section{Research Instrument and Measures}

A 31-page questionnaire was specifically constructed for this study, based on (i) a review of the relevant literature and existing research instruments on stress, coping, participation and influence, social support, and health; (ii) in-depth interviews with selected hourly and salaried employees and union and management representatives; and (iii) researcher observations derived from numerous contacts (meetings, conversations, site visits) with the study site.

The data presented here are based on analysis of selected measures of (1) physical and psychosocial sources of stress at work; (2) sources of stress outside of work; (3) conflict or interference experienced between work and nonwork situations; (4) feelings about work and life outside of work; (5) physical and mental health; and (6) demographic characteristics.

Several multiple-item measures were constructed. As a first step in developing these measures, we carried out a set of factor analyses on the major classes of variables. Additive indices were developed on the basis of the results of the factor analysis. The reliability of these indices was calculated using Cronbach's alpha as a measure of the average interitem correlation. Only those measures achieving at least moderate to high internal consistency reliability (alpha >.60) and comprised of logically related items were used in the analysis. A description of the measures used, along with their reliability estimates, scale ranges, means, and standard deviations, is presented in the Appendix.

The specific measures used here were selected on the basis of their reliability estimates and also because they were thought to cover each of the relevant domains. Seven measures of work-related stressors were included in the analysis: quality of physical work environment ( 3 items), task demands (workload and responsibility) ( 5 items), information and communication problems ( 3 items), interpersonal demands ( 4 items), problems with coworkers ( 2 items), 
problems with supervisors ( 2 items), and (good) job security ( 5 items). Two measures of stressors outside of work were used: a measure of ongoing problems or chronic stressors ( 9 items) and a measure of stressful life events (8 items). There were three measures of work-nonwork conflict or interference: work interferes with nonwork ( 3 items), life outside of work interferes with work ( 3 items), and ruminations about work outside of work ( 2 items). Feelings at work and outside of work were measured by two separate indices: negative feelings at work ( 4 items) and negative feelings outside of work (4 items). There were two measures of physical and mental health: depressive symptoms (11 items from the CES-D depression scale) (Radloff, 1977) and physical symptoms (17 items).

\section{Data Analysis}

The analyses in this article examine the relationship among stressors at work, stressors outside of work, conflict or interference between work and nonwork, feelings about work and nonwork, and health. The statistical methods used for examining these relationships are correlations and ordinary least-squares regression. Bivariate correlation coefficients were calculated to assess the crude relationships between one class of variables and another. Multiple regression techniques were used to assess the independent associations of work stressors, nonwork stressors, and work-nonwork interference, respectively, with feelings and health, while controlling for demographic characteristics and the other relevant classes of variables.

\section{RESULTS}

\section{Stress at Work and Outside of Work}

The first question addressed in our analyses concerns the nature of the relationship between stressors at work and stressors outside of work (Question 1). Zero-order correlations (Table I) show that, overall, the association between work (variables 1-7) and nonwork (variables 8 and 9) stressors are rather weak. Of 14 correlations (enclosed by the dashed box in Table I), half are below .10, four are between .10 and .19, and three are between .20 and .25 . In contrast, correlations within each of these two domains generally exceed .25 . To the extent that a correlation between the two types of stressors is present, it appears to be in a positive direction. That is, there is a slight tendency for people with high levels of job stressors also to report high levels of nonjob stressors, and vice versa. 


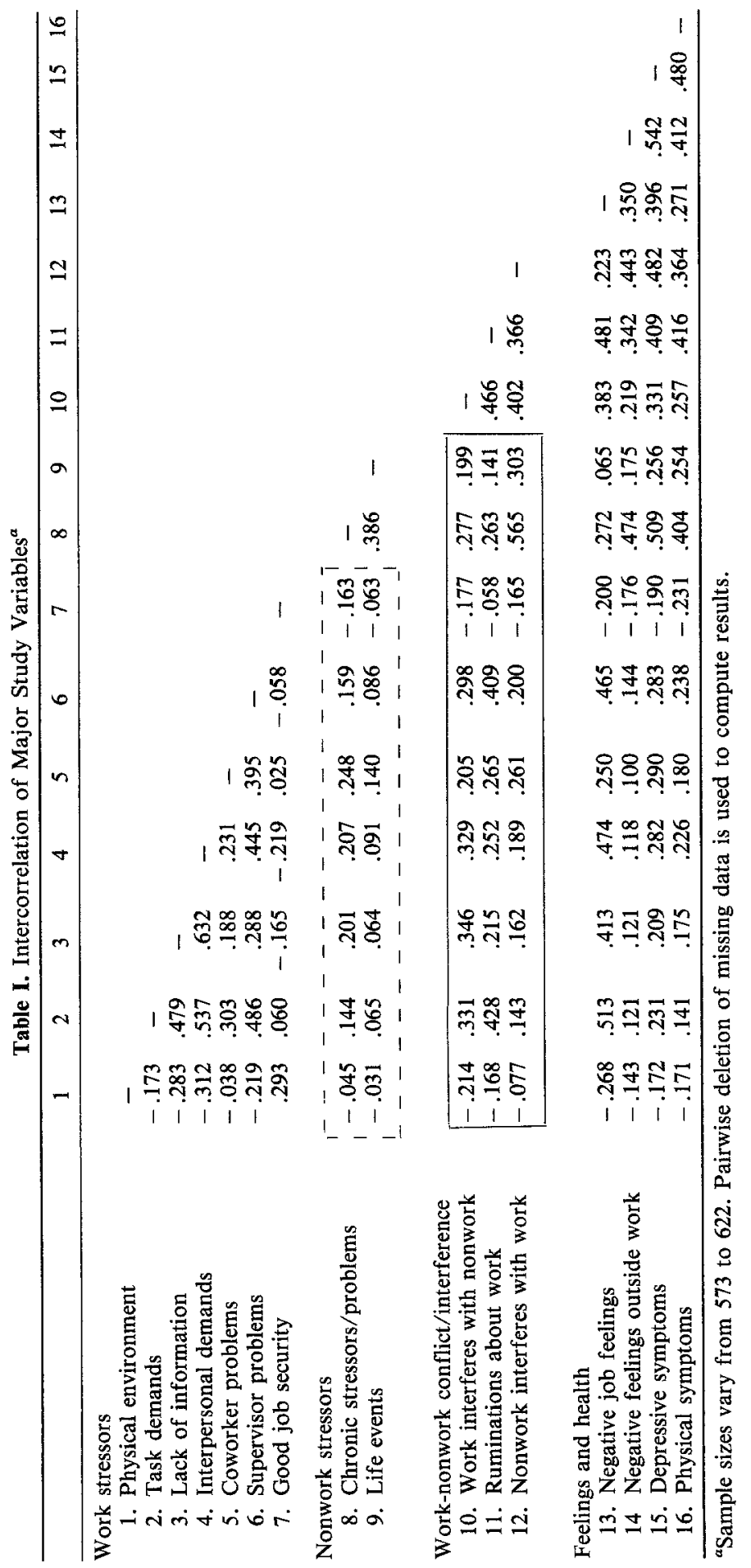




\section{Work Stress, Nonwork Stress, and Conflict}

Next we address the question of whether stress in one domain of life interferes with or creates conflict in another (Question 2). Several of our analyses shed light on this issue. The mean levels of each of the three measures of work-nonwork conflict (work interfering with nonwork, nonwork interfering with work, and ruminations about work outside of work) are presented in the Appendix. As indicated, the levels are almost identical-ranging from 1.83 to 1.87 on a 3-point scale. This suggests that work interferes with life outside of work as much as nonwork life interferes with work.

The zero-order correlations between each of the stressors (variables 1-9) and conflict (variables 10-12) measures are presented in the solid box within Table I. These relationships follow logical patterns of association. Each is in the expected direction. That is, stressful work conditions (e.g., problems with supervisors at work and workload demands) are positively associated with work-nonwork interference (e.g., feeling that work life interferes with nonwork life), while positive conditions (e.g., having good job security) are negatively associated with conflict. There is also some degree of specificity in these relationships. Interference of work with nonwork life is more strongly associated with work stressors than with nonwork stressors. Similarly, interference of life outside of work with working life is much more strongly associated with nonwork stressors than with work stressors.

Next we examined the independent relationship between each of the two classes of stressors (at work, outside of work) and the relevant measure of interference. To examine the independent effects of job stressors on interference of work with life outside of work, we used a stepwise regression procedure in which we first entered all the demographic variables into the equation, then entered all of the nonwork stressors, and finally, entered all of the job stressor measures. Similarly, to examine the independent association of nonwork stressors and interference with work, we controlled first for demographic characteristics and then for work stressors.

The results of both sets of analyses are presented in Table II. Overall, they are consistent with the results of the bivariate analyses. In Table II, we see that interference of work with nonwork and ruminations about work are more a function of job stressors than nonjob stressors. Work stressors increased the variance explained in these two dependent variables by .123 and .196 , respectively, over the variance explained by the demographic and nonwork variables. The latter add only .073 and .067 , respectively, to the variance explained in these dependent variables net of the demographic variables (and only .028 when computed net of the work stress variables). The converse is also true, as seen also in Table II: problems outside of work interfering with work are more strongly related to stressful conditions outside of work than at work. Nonwork stressors increase the variance explained in the dependent variable by .239 over the variance explained by the demographic 


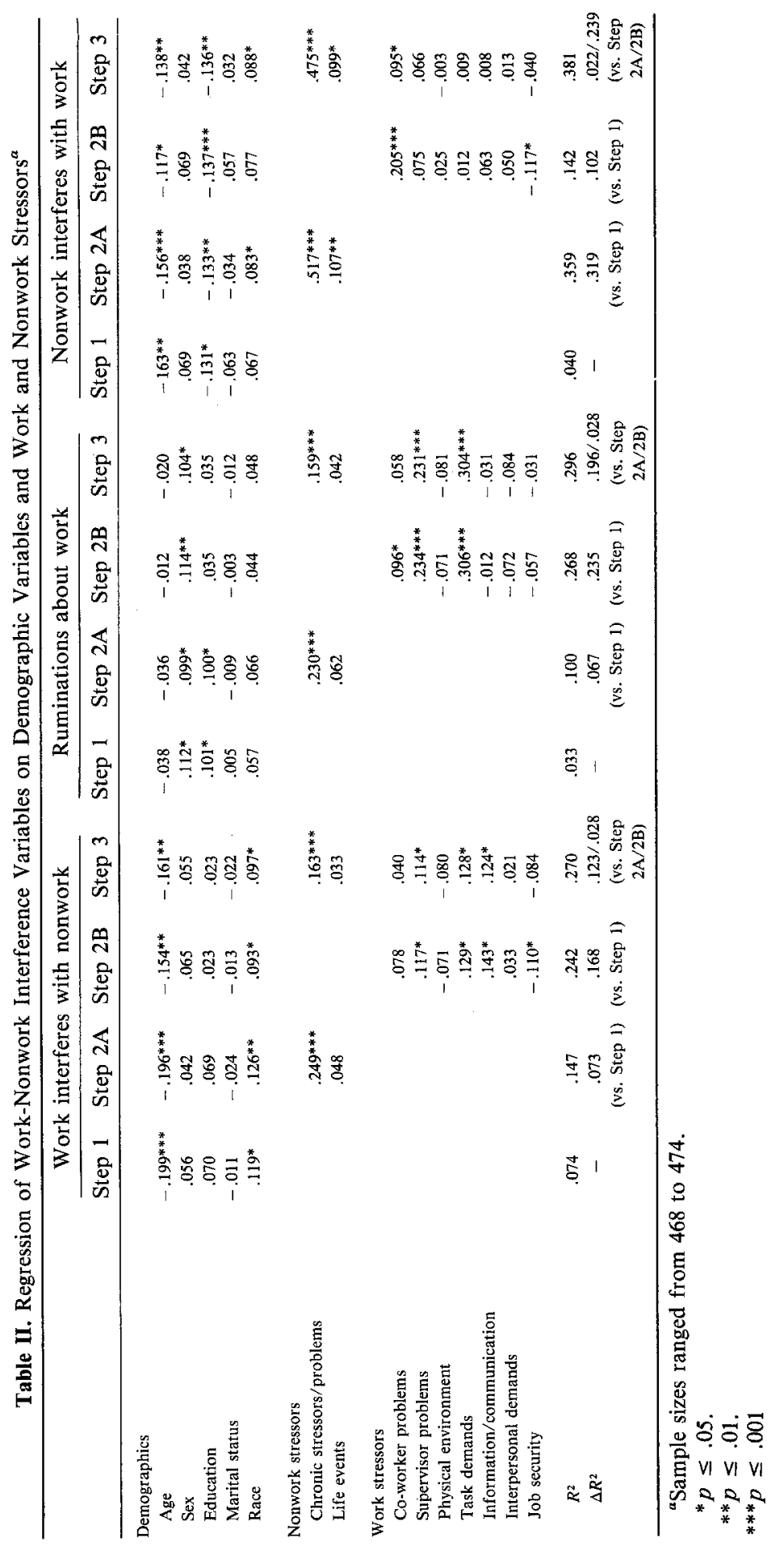


and work stressor variables, with the latter adding only .102 to variance explained in this dependent variable, net of the demographic variables (and only .022 net of both the demographic and nonwork stress variables). Nonwork stressors are slightly more strongly associated with conflict than are work stressors.

\section{Relationship of Stressors to Feelings and Health}

Next we turn to the relationship of work and nonwork stressors to health and well-being (Question 3). The bivariate relationships between stressors and feelings and health variables also reveal logical and consistent patterns (see Table I). Negative job feelings (row 13 in Table I) are more strongly predicted by job stressors than nonjob stressors (mean $r=.37$ and .17 , respectively). Conversely, negative feelings outside of work (row 14 in Table I) are more strongly predicted by stressors outside of work than at work (mean $r=.32$ and .14 , respectively). On average, the correlations are approximately twice as strong for the relevant type of stressors and feelings. Correlations of the nonwork stressors with mental and physical health are somewhat larger (especially in the case of chronic stressors/problems) than the correlation of the work stressors with these health variables, but both are sizable.

To examine the independent relationship of each class of stressors to feelings and health, we conducted a series of stepwise regression analyses, controlling for demographic characteristics and for the appropriate class of stressors. The procedures used for this set of analyses were the same as for the work-nonwork conflict analyses, as described above. The results are presented in steps $2 \mathrm{~A}$ and $2 \mathrm{~B}$ and step 3 throughout Table III and follow the same pattern as the bivariate associations. That is, net of the demographic variables, job stressors exert a stronger net effect on negative job feelings than do nonwork stressors (change in $R^{2}=.36$ and .07 , respectively). Conversely, nonwork stressors exert a stronger net effect on nonwork feelings than work stressors (change in $R^{2}=.22$ and .06 , respectively).

Each class of stressors is independently and significantly associated with both physical and mental health outcomes, even after controlling for the other. Comparing the relative magnitude of these two types of associations net of demographic variables and the other stressors, nonjob stressors have a stronger effect than job stressors on both depressive symptoms $\left(R^{2}\right.$ change $=.159$ and .079 , respectively $)$ and physical symptoms $\left(R^{2}=\right.$ change $=.106$ and .069 , respectively).

\section{Work-Nonwork Interference and Health}

Finally, we address the question of whether work-nonwork conflict is, in and of itself, associated with feelings and health (Question 4). The bivari- 


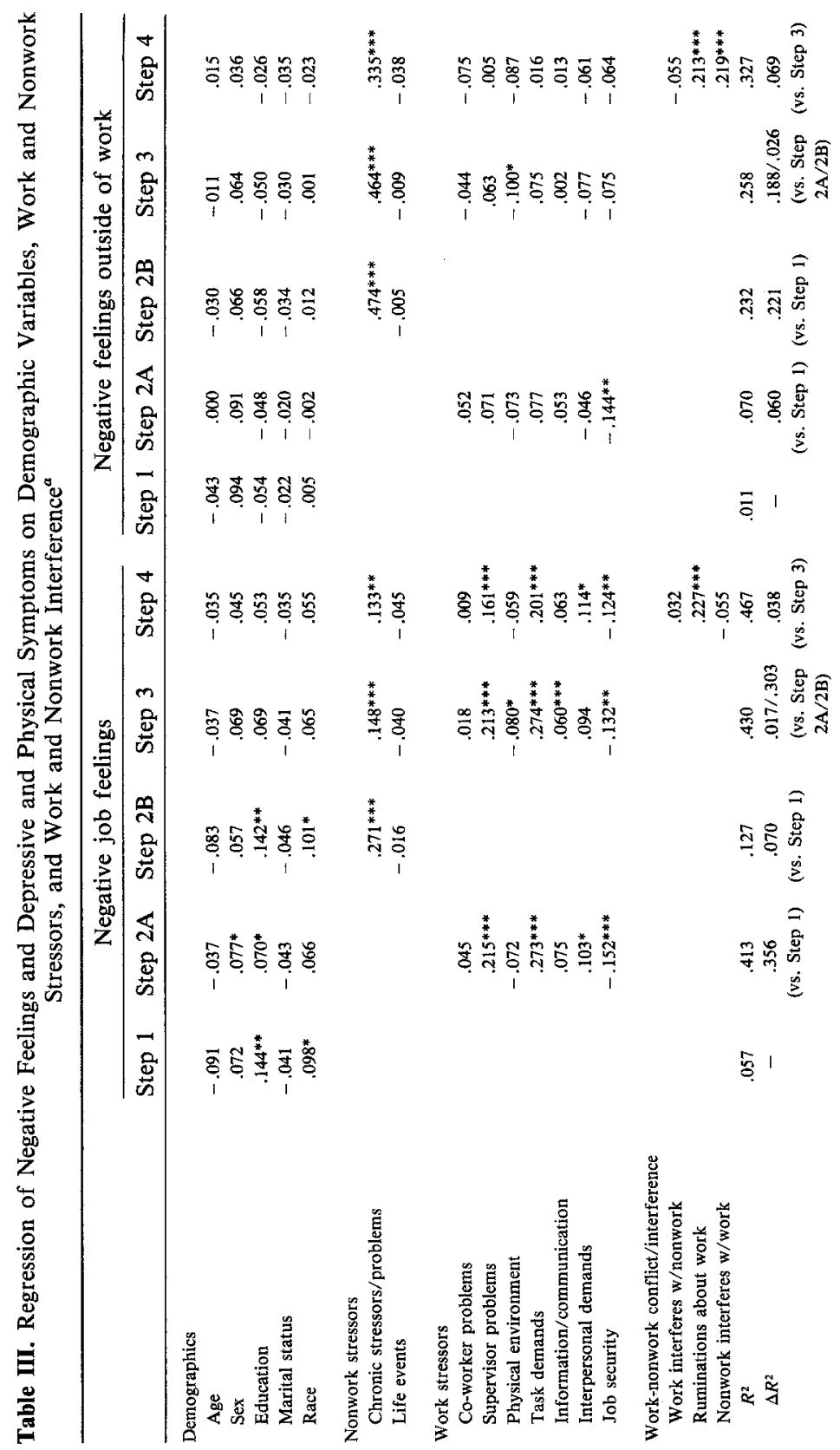




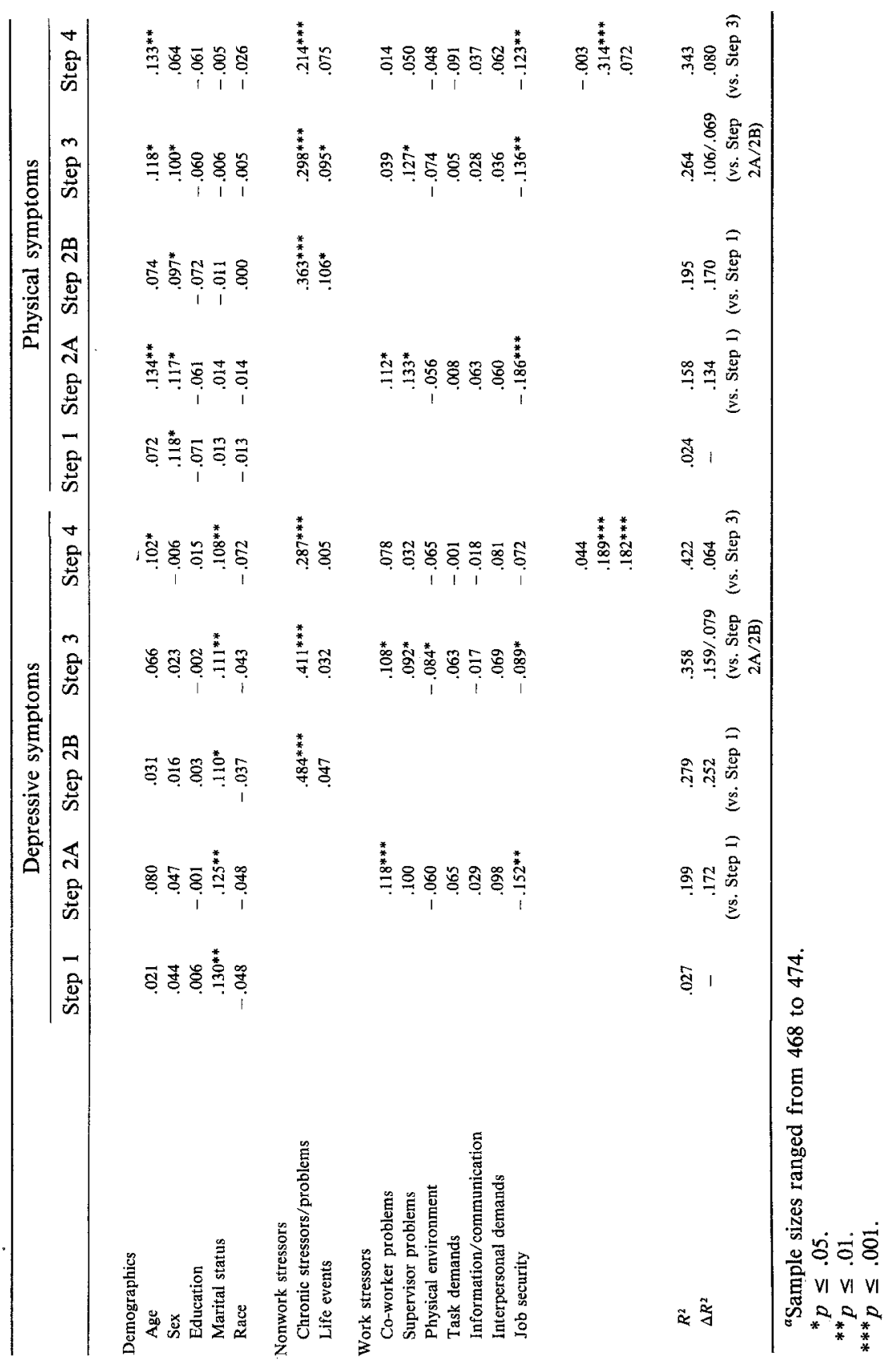


ate correlations (Table I) are moderately strong (ranging from $r=.22$ to .48 ) and are all in the expected direction. (See correlations among the variables in columns 10-12 with the variables in rows 13-16.)

The results of stepwise regressions, examining the impact of worknonwork conflict on health, while controlling for demographic characteristics and the main effects of work and nonwork stressors are shown in step 4 in Table III. These data indicate that work-nonwork conflict - in both directions - is significantly associated with negative feelings and adverse health symptoms, above and beyond the effects of work stressors and nonwork stressors. Ruminations about work and nonwork interference with work appear to be more important types of conflict than interference of work with nonwork life. Only the ruminations variable affects all four dependent variables net of all other independent variables. These work-nonwork conflicts significantly mediate the impact of nonwork and work stressors on health and well-being.

\section{DISCUSSION}

We believe that the results of our analyses contribute to an overall understanding of the relationship among work stress, stress outside of work, and have an independent, additive impact on feelings and health. In this population, nonwork, which occupies a larger portion of people's lives and is usually more important to them (e.g., Veroff et al., 1981), not surprisingly is somewhat more strongly related to health.

Second, although work and nonwork represent two independent sources of stress in people's lives, the data also show that stress in one domain may exacerbate conflict in the other. There is no clear evidence that "spillover" is greater in one direction versus another. Mean values and bivariate correlations among the various measures are comparable. In the multiple regression analyses, both work- and nonwork-generated sources of stress were significantly associated with adverse physical and mental health.

As noted earlier, many previous studies on the relationship between work and nonwork assume, a priori, that one domain is more important than the other. Our data suggest that both types of work-nonwork conflict should be considered in any investigation and that an a priori assumption regarding their causal priority would be ill-advised.

Third, our data indicate that sources of stress both on and off the job independently affect feelings and health. We observed some specificity in this relationship. Specifically, the way people feel at work is more strongly predicted by stressors at work than outside of work. Feelings outside of work are largely predicted by stressors outside of work. Such findings help to confirm the discriminant validity of self-reported measures. 
This finding also has particular significance in light of current approaches to health promotion and stress management, as practiced by many worksite programs and medical departments. A common focus of such programs is on helping the troubled employee, who may experience problems on the job, ostensibly as a result of physical, mental, personal, or other problems outside of the job (see, for example, Dickerson and Kaminer, 1986). Thus, such programs usually focus on changing individual risk factors (e.g., smoking, cholesterol, overweight) (Fielding, 1984) or train people to relax or manage stressful situations, but rarely do such programs consider reducing work-related sources of stress (McLeroy et al., 1984). Our findings do not support the assumption that people who have problems at work are simply bringing their problems from home to work with them. Instead, stresses occurring in these major life domains are relatively independent of each other and have an independent, additive impact on feelings and health. In this population, nonwork, which occupies a larger portion of people's lives and is usually more important to them (e.g., Veroff et al., 1981), not surprisingly is somewhat more strongly related to health.

Fourth, we found that chronic stressors - both on and off the jobwere more strongly related to feelings and health than were life events. Such findings are consistent with many recent studies which emphasize the importance of considering both types of stressors (Kanner et al., 1981; DeLongis et al., 1982; Ivancevich, 1986).

Finally, our data indicate that work-nonwork conflict-originating from either direction - may be an added source of stress and adversely affect physical and mental health. We should note, however, that we found no evidence that work and nonwork stressors interact in predicting health and well-being. That is, work and nonwork stressors each additively predict perceptions of conflict and reports of health and well-being, and conflict increases the effect on health and well-being. But we find no evidence that having high nonwork stress increases the effects of work stressors or vice versa.

Taken as a whole, our findings both make use of and add to a multidisciplinary approach to understanding the relationship between socioenvironmental stress and health. According to this view, stress may result from a broad range of conditions - e.g., in one's work, family, and community life. These conditions combine with each other and with characteristics of the individual to produce various physical and mental health states (e.g., McLean, 1979; House, 1980). Unfortunately, there is only limited empirical evidence to substantiate this multicause/multieffect model. Much of previous research on psychosocial stress and health has tended to focus on one particular source or type of stress. For example, research on stressful life events has been concerned primarily with traumatic occurrences which take place outside of the work domain such as family illness, death, and other 
losses (Holmes and Rahe, 1974; Dohrenwend and Dohrenwend, 1981). At the same time, much of the research on occupational stress, while acknowledging the theoretical importance of life outside of work has focussed almost exclusively on working conditions (Caplan, 1980; House, 1980; McLean, 1979). By examining in the same study the role of work and nonwork environment and the resultant stress and conflict they produce, we are able to explain a much greater portion of the variance in health outcomes than previous studies which have only examined one of these sets of factors (e.g., Rabkin and Struening, 1976). As such, we can substantially increase our understanding of the socioenvironmental causes of human dissatisfaction and illness.

In spite of the new information which these data provide, a number of substantive and methodological issues are raised here which also suggest directions for further analysis and future research. These data are selfreported and cross-sectional (although our model assumes a causal ordering among stressors, work-nonwork interference, feelings, and health). Indeed there is evidence from longitudinal research to support causal inferences in this direction (Kohn and Schooler, 1978; Karasek, 1981). However, because all of the data used in these analyses were collected by self-report at one point in time, we caution against any firm causal assertions. As stated earlier, these data are part of a longitudinal investigation. It is our intention to examine changes in work and nonwork sources of stress and their relationship to health in future panel analyses.

Another issue relates to the specificity and comparability of our measures of stressors. We used three measures of work-nonwork conflict: two which measured work interference with nonwork and one which measured the converse. Equivalent mean scores were observed on each of these measures. We interpreted this finding to mean that work interferes with life outside of work as much as nonwork life interferes with work. We caution, however, that such an interpretation is based on the untested assumption that each measure is an equally sensitive indicator of conflict. Further multimethod studies are required to identify whether there are specific kinds of stressors in the work and nonwork environments, respectively, that are more likely to produce conflict.

We also used two composite measures of nonwork stress - one which measures life events and the other which measures chronic stressors. By utilizing composite measures, we are unable to identify which specific stressors (e.g., financial, marital, parental) most strongly affect worklife or health. Thus these data cannot be used to target specific areas for stress-reducing interventions, but they do suggest that nonwork stressors should be examined when designing such worksite programs. Further analysis is required to iden- 
tify which specific sources of nonwork stress are most critical to the health and well-being of this and other worksite populations.

Another issue relates to the representativeness of our sample. Sixty-six percent of those eligible filled out the survey. Unfortunately, no data were available to us on the $34 \%$ of employees who did not participate. Although it is possible that nonparticipants may have differed from participants in certain demographic or job characteristics, we are unaware of any specific selection factors which would substantially alter the overall direction of the results reported here.

Related to this, there is also some question regarding the generalizability of these findings to other occupational groups and other settings. Our and others' research - as summarized here-indicates that role characteristics are an important determinant of health. These role characteristics may vary according to an individual's position in the social structure. For example, stressful job characteristics-e.g., high demands and low control-are inversely related to one's position in the organizational hierarchy (Karasek, 1981). Outside of work, family demands and pressures have been shown to differ for men and women, even though both may occupy the same roles (Froberg et al., 1986). Thus it is reasonable to argue that the sources and types of stress and conflict people experience may vary in different nonwork situations. A comparison of our findings on work-nonwork conflict with those of another suggest that this may be the case. As cited earlier, Beutell and O'Hare (1987) found work to be a greater source of work-nonwork conflict than nonwork. Their sample consisted of managerial level employees who were also attending night school. In contrast, we found work and nonwork to be roughly equal sources of conflict. Participants in the former study probably spent more hours away from home and were different, sociodemographically than our study population. Moreover, in our study, we controlled for demographic characteristics but did not examine their interaction with stress in predicting conflicts, feelings, or health. These divergent sets of findings suggest a need to explore how sociodemographic factors may interact with role patterns and characteristics and potentially have an impact on health. We plan to explore these issues in future analysis of our data.

In conclusion, in spite of the methodological limitations outlined here, the present findings provide substantial evidence that both work stress and nonwork stress may lead to conflict between the two domains, and each is independently associated with health. The data also have implications for stress reduction and health promotion programs. Our data suggest that programs aimed at reducing sources of stress in both the work and nonwork environments will have a greater potential for improving physical and psychological well-being than programs which focus on only one of these broad sets of factors. 


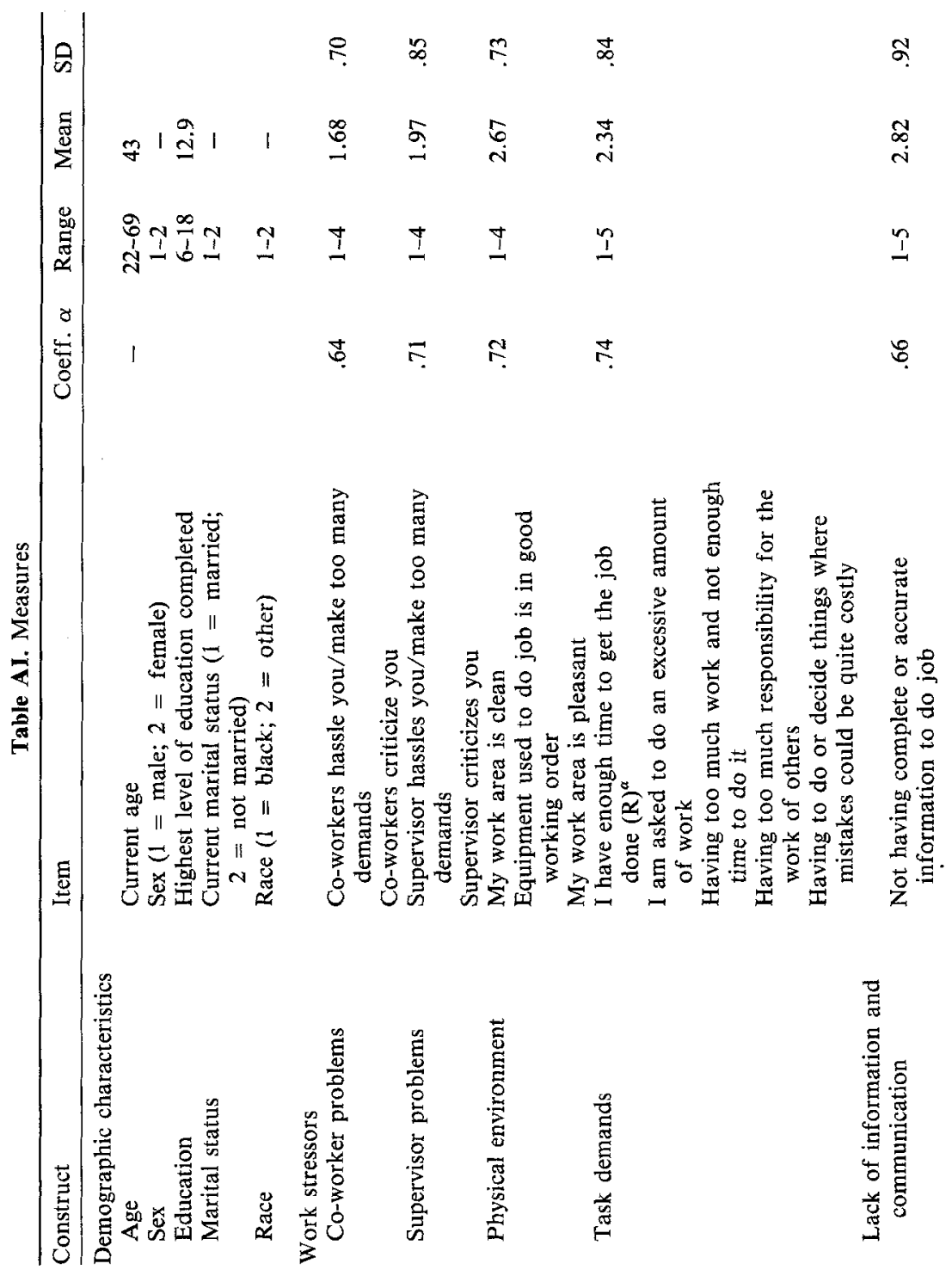




\begin{tabular}{|c|c|c|c|}
\hline$\infty$ & $n$ & 8 & \\
\hline 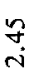 & $\stackrel{\infty}{-\infty}$ & $\stackrel{\infty}{\stackrel{\infty}{\longrightarrow}}$ & 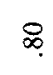 \\
\hline$n$ & $I$ & $\begin{array}{l}5 \\
\stackrel{0}{0}\end{array}$ & 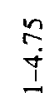 \\
\hline & ర్త & $\stackrel{\infty}{\imath}$ & $\infty$ \\
\hline
\end{tabular}

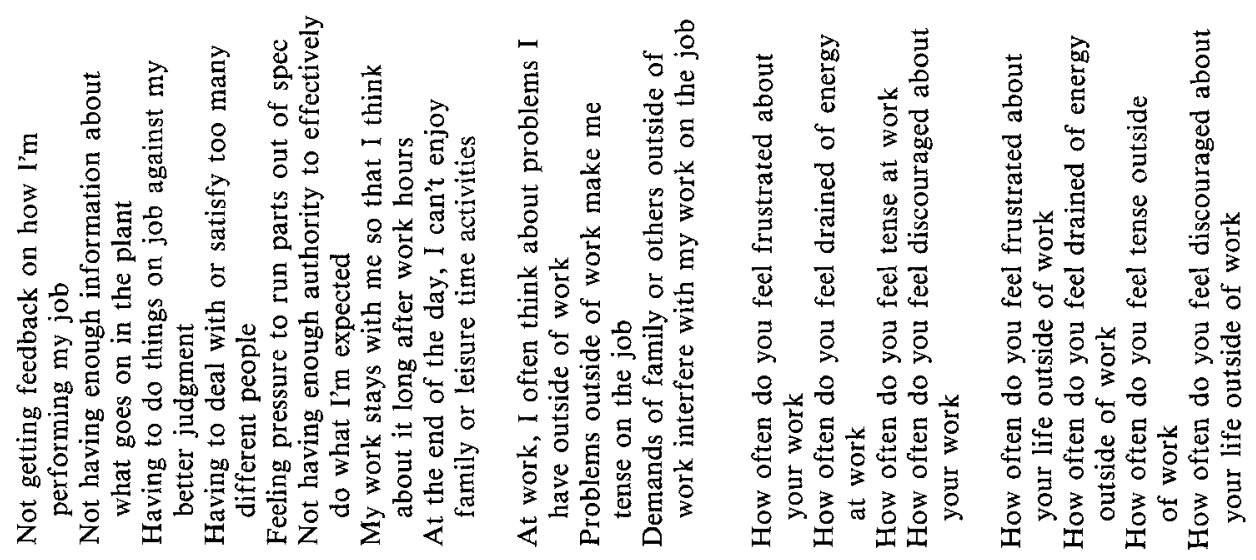

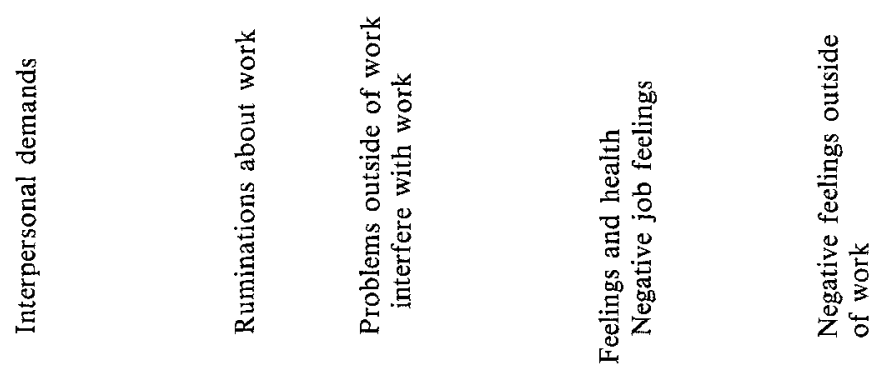




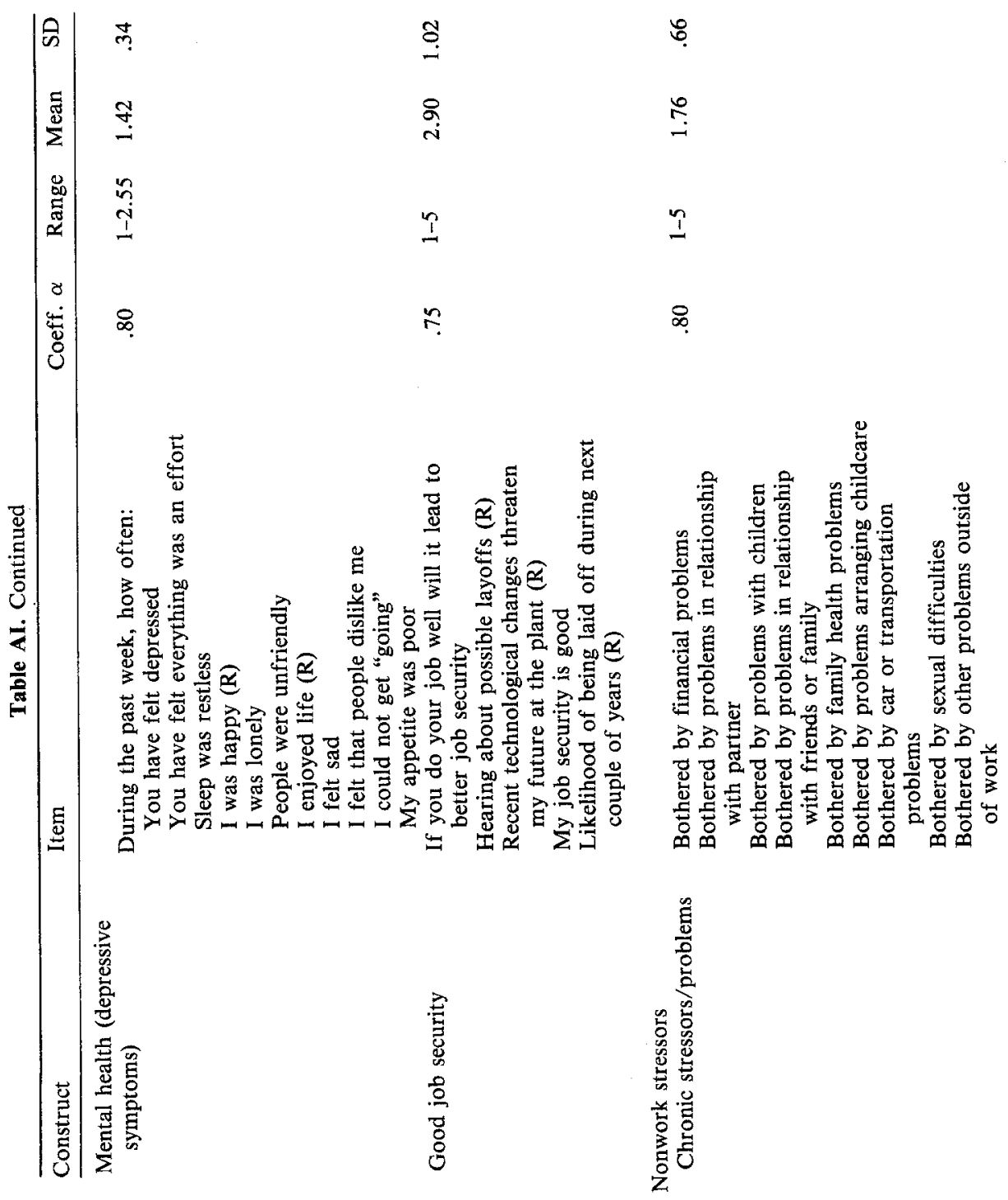



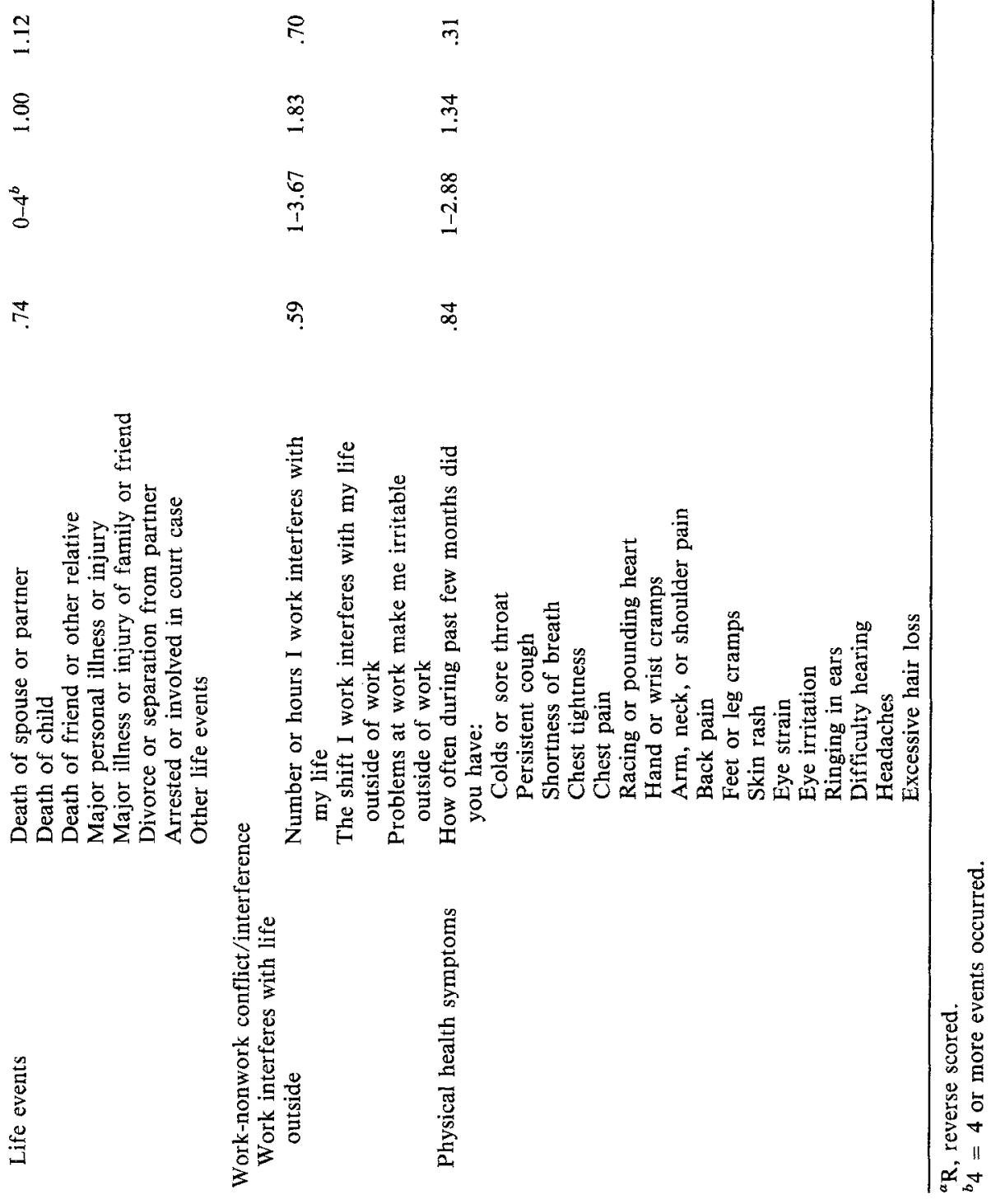


\section{REFERENCES}

Beutell, N. J., and O'Hare, M. M. (1987). Work-nonwork conflict among MBAs: Sex differences in role stressors and life satisfaction. Work Stress 1(1): 35-42.

Burke, R. J., and Bradshaw, P. (1981). Occupational and life stress and the family. Small Group Behav. 12(3): 329-375.

Caplan, R. D., Cobb, S., French, J. R. P., Harrison, R. V., and Pinneau, S. R. (1980). Job Demands and Worker Health, Institute for Social Research, University of Michigan, Ann Arbor.

Delongis, A., Coyne, J. C., Dakof, G., Folkman, S., and Lazarus, R. S. (1982). Relationship of daily hassles, uplifts and major life events to health status. Health Psychol. 1: 119-136.

Dickerson, O. B., and Kaminer, A. J. (eds.), (1986). The troubled employee. Occup. Med. State Art Rev. 1(4).

Dohrenwend, B. P., and Dohrenwend, B. S. (1981). Some possible relations between stressful work events, other life events and psychopathology. In Gardell, B., and Johansson, G. (eds.), Working Life: A Social Science Contribution to Work Reform, John Wiley and Sons, New York.

Fielding, J. E. (1984). Health promotion and disease prevention at the worksite. Annu. Rev. Publ. Health 5: 237-265.

Frankenhaeuser, M., and Gardell, B. (1976). Underload and overload in working life. J. Hum. Stress 2: 35-46.

Froberg, D., Gjerdingen, D., and Preston, M. (1986). Multiple roles and women's mental and physical health: What have we learned? Women Health 11(2): 79-96.

Gore, S., and Mangione, T. W. (1983). Social roles, sex roles and psychological distress: Additive and interactive models of sex differences. J. Health Soc. Behav. 24 (Dec.): 300-312.

Gove, W. R., and Geerken, M. R. (1977). The effect of children and employment on the mental health of married men and women. Social Forces 56: 66-76.

Gove, W. R., and Tudor, J. F. (1973). Adult sex roles and mental illness. Am. J. Sociol. 78: 812-835.

Haynes, S. G. (1987). The effect of high job demands and low control on the health of employed women. In Quick, J. S., Bhagat, R. S., Dalton, J., and Quick, J. D. (eds.), Work Stress Health Care, Praeger Scientific Press, New York.

Hibbard, J. H., and Pope, C. R. (1983). Gender roles, illness orientation and use of medical services. Soc. Sci. Med. 17: 129-137.

House, J. S. (1980). Occupational Stress and the Physical and Mental Health of Factory Workers, University of Michigan, Institute for Social Research, Ann Arbor.

House, J. S., and Cottington, E. M. (1986). Health and the workplace. In Aiken, L. H., and Mechanic, D. (eds.), Applications of Social Science to Clinical Medicine and Health Policy, Rutgers University Press, New Brunswick, NJ, pp. 392-416.

Israel, B. A., Schurman, S. J., and House, J. S. (1989). Action research on occupational stress: Involving workers as researchers. Int. J. Health Serv. 19: 135-155.

Israel, B. A., Schurman, S. J., House, J. S., Heaney, C. A., and Mero, R. P. (1989). The relation of personal resources, participation, influence, interpersonal relationships and coping strategies to occupational stress, job strains and health: A multivariate analysis. Work Stress 3: 163-194.

Ivancevich, J. M. (1986). Life events and hassles as predictors of health symptoms, job performance and absenteeism. J. Occup. Behav. 7: 39-51.

Kanner, A. D., Coyne, J. C., Schaefer, C., and Lazarus, R. S. (1981). Comparison of two modes of stress measurement: Daily hassles and uplifts versus major life events. $J$. Behav. Med. 4: 1-39.

Kanter, R. M. (1977). Work and Family in the US: A Critical Review and Agenda for Research and Policy, Russell Sage Foundation, New York.

Karasek, R. A. (1981). Job socialization and job strain: The implications of two related psychosocial mechanisms for job design. In Gardell, B., and Johanson, G. (eds.), Working Life: A Social Science Contribution to Work Reform, John Wiley and Sons, New York, pp. 75-95. 
Karasek, R. A., Baker, D., Marxer, F., Ahlbom, A., and Theorell, T. (1981). Job decision latitude, job demands and cardiovascular disease. Am. J. Publ. Health 71: 694-705.

Kittel, F., Kornitzer, M., and Drmaix, M. (1980). Coronary heart disease and job stress in two cohorts of bank clerks. Psychother. Psychosom. 34: 110-123.

Kohn, M., and Schooler, C. (1978). The reciprocal effects of the substantive complexity of work and intellectual flexibility: A longitudinal assessment. Am. J. Sociol. 84(1): 24-52.

Levi, L. (1981). Preventing Work Stress, Addison-Wesley, Reading, MA.

McLean, A. (1979). Work Stress, Addison-Wesley, Reading, MA.

McLeroy, K. R., Green, L. W., Mullen, K. D., and Foshee, V. (1984). Assessing the effects of health promotion in worksites: A review of stress program evaluations. Health Educ. Q. 11(4): 379-401.

Muller, C. (1986). Health and health care of employed women and homemakers: Family factors. Women and Health 11(1): 7-26.

Navarro, V., and Berman, D. (1981). Health and Work Under Capitalism, Baywood, Farmingdale, NY.

Papenek, H. (1973). Men, women and work: Reflections on the two-person career. Am. J. Sociol. 78: 853-872.

Rabkin, J., and Struening, E. (1976). Life events, stress and illness. Science 194: 1013-1020.

Radloff, L. S. (1977). The CES-D Scale: A self-report depression scale for research in the general population. Appl. Psychol. Measure. 1: 385-401.

Roemer, M. I. (1984). The public/private mix of health care sector financing: International implications. Public Health Rev. 12(2): 119-130.

Staines, G. L. (1980). Spillover versus compensation: A review of the literature on the relationship between work and nonwork, Hum. Relat. 33(2): 111-129.

Staines, G. L., and Pleck, J. H. (1983). The Impact of Work Schedules on the Family, University of Michigan, Institute for Social Research, Ann Arbor.

Verbrugge, L. M. (1983). Multiple roles and physical health of women and men. J. Health Soc. Behav. 24: 16-30.

Verbrugge, L. M. (1986). Role burdens and physical health of women and men. Women Health 11(1): 47-78.

Veroff, J., Douvan, E., and Kulka, R. A. (1981). Mental Health in America: Patterns of HelpSeeking from 1957 to 1976, Basic Books, New York.

Waldron, I. (1980). Employment and women's health: An analysis of causal relationships. Int. J. Health Serv. 10(3): 435-454. 